\section{Changing challenges in the control of blindness in children}

\begin{abstract}
One cannot address issues of control of blindness in children without first considering the epidemiology, as this allows priorities to be determined and appropriate strategies to be delineated. Control does not occur within a vacuum, and so it is also important to understand the context in which programmes are to be implemented, particularly in relation to development and poverty - the distal risk factors that are powerful determinants of the incidence of disease in populations.

Interventions need to be considered from the perspective of patients as well as providers if services are to be acceptable and appropriate. Eye (2007) 21, 1338-1343; doi:10.1038/sj.eye.6702841

Keywords: childhood blindness; measles; retinopathy of prematurity; control strategies; VISION2020; development
\end{abstract}

\section{Epidemiology of blindness in children}

Determining the prevalence and causes of rare diseases is challenging, and blindness in children is no exception. The 'gold standard' cross sectional prevalence survey poses many difficulties as far as children are concerned, as measuring visual acuity is very difficult in a field setting, particularly in young and multiply disabled children, and enormous sample sizes are required to give reasonable precision and reliable data on causes. As the surveys need to be large, they are very expensive. In addition, children may be away at school, or staying with relatives and blind children may be in residential care. For all these reasons, data from population based surveys are very limited. ${ }^{1}$ Interpretation of the available data is compromised by the fact that different age groups have been studied, different definitions of blindness used and causes categorised in different ways. Having said all this, the available data suggest that the prevalence and causes of blindness in children are associated with levels of development, and under 5 mortality rates can be used as a reasonably good proxy. ${ }^{2}$ Indeed, the International Vitamin A Consultative Group has recently recommended that under 5 mortality rates be used to predict whether communities of children are at risk of vitamin A deficiency, an important cause of blindness as well as mortality in children. ${ }^{3}$ Under 5 mortality rates have been used to estimate the prevalence of blindness in every country in the world (Figure 1) and hence the number of blind children globally, which currently stands at 1.4 million. $^{2}$ Almost $3 / 4$ of these children live in developing countries.

Information on the causes of blindness in children has mainly come from examining children in special education, as they are a readily available captive audience, and most data have been collected using the World Health Organization's classification system. ${ }^{4}$ However, data are becoming increasingly available from population-based studies of differing designs. The available data (on almost 15000 blind children from 43 countries), although some are subject to selection bias, suggest that the causes of blindness vary enormously from region to region. Combining prevalence estimates with demographic and causes data allows the pattern of blindness in children in different communities to be compared (Table 1). From this, it becomes apparent that priorities for control need to vary from region to region. In considering only avoidable causes, corneal scarring (due to vitamin A deficiency, measles infection, ophthalmia neonatorum and the use of harmful traditional eye remedies) (Figure 2) predominates in the poorest communities. ${ }^{5}$ Cataract is becoming an increasingly important cause in poor countries where there are programmes in place for the control of measles and vitamin A deficiency, ${ }^{6}$ retinopathy of prematurity is often the single commonest cause in the middle income countries of Latin 


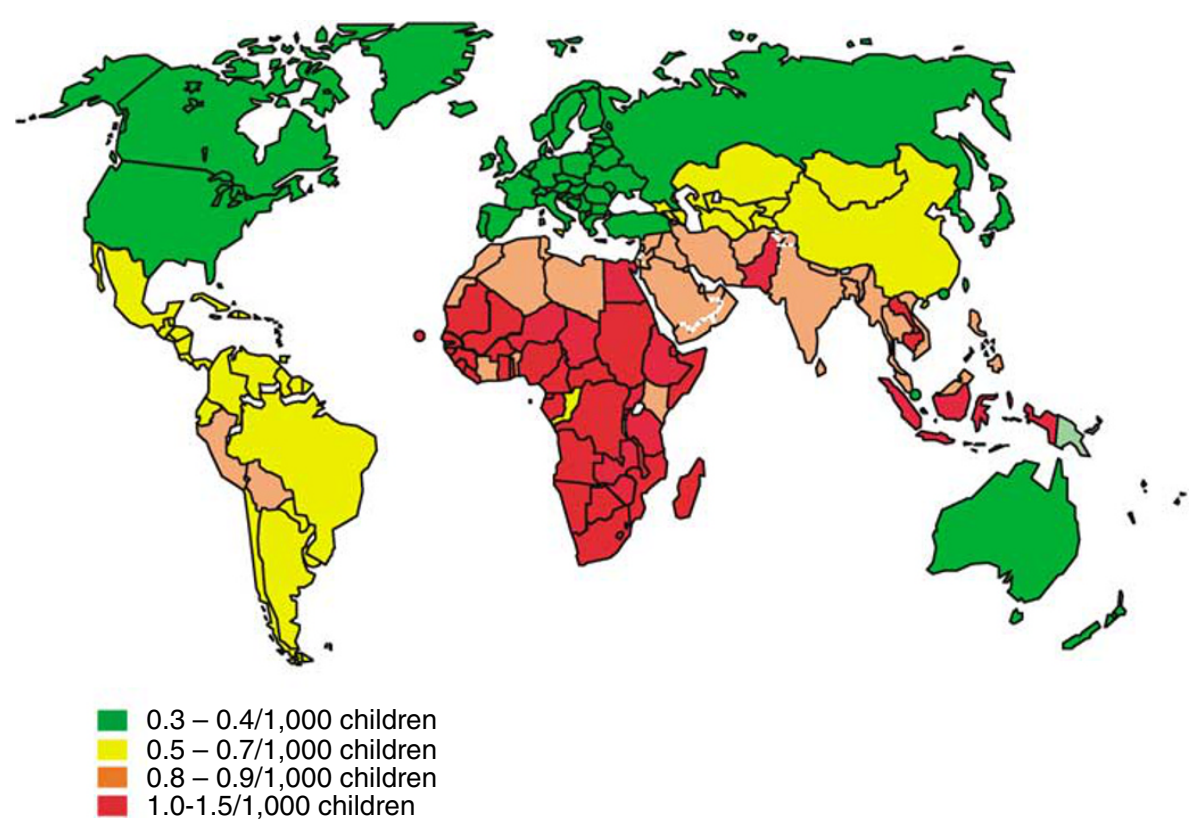

Figure 1 Estimates of the prevalence of blindness in children, using under 5 mortality rates as a proxy indicator.

Table 1 Magnitude and pattern of cause of blindness in children

\begin{tabular}{|c|c|c|c|c|c|c|}
\hline \multirow[b]{2}{*}{$\begin{array}{l}\text { Level of } \\
\text { development }\end{array}$} & \multirow[b]{2}{*}{$\begin{array}{l}\% \text { of population } \\
\text { aged } 0-15 \text { years }\end{array}$} & \multicolumn{5}{|c|}{ Per 10 million total population } \\
\hline & & $\begin{array}{l}\text { No. of children } \\
\text { (million) }\end{array}$ & $\begin{array}{c}\text { Prevalence of } \\
\text { blindness }\end{array}$ & $\begin{array}{l}\text { Number of blind } \\
\text { children }\end{array}$ & Major causes & Number affected \\
\hline \multirow[t]{4}{*}{ High income } & 20 & 2 & $0.3 / 1000$ & 600 & Scar & 0 \\
\hline & & & & & Cataract/glaucoma & 60 \\
\hline & & & & & $\mathrm{ROP}$ & 60 \\
\hline & & & & & $\begin{array}{l}\text { Others }{ }^{\mathrm{a}} \text { (mainly } \\
\text { CNS) }\end{array}$ & 480 \\
\hline \multirow[t]{4}{*}{ Middle income } & 30 & 3 & $0.6 / 1000$ & 1800 & Scar & 0 \\
\hline & & & & & Cataract/glaucoma & 360 \\
\hline & & & & & ROP & 450 \\
\hline & & & & & Others $^{\mathrm{a}}$ & 990 \\
\hline \multirow[t]{4}{*}{ Low income } & 40 & 4 & $0.9 / 1000$ & 3600 & Scar & 720 \\
\hline & & & & & Cataract/glaucoma & 720 \\
\hline & & & & & $\mathrm{ROP}$ & 0 \\
\hline & & & & & Others $^{a}$ & 2160 \\
\hline \multirow[t]{4}{*}{ Very low income } & 50 & 5 & $1.2 / 1000$ & 6000 & Scar & 3000 \\
\hline & & & & & Cataract/glaucoma & 900 \\
\hline & & & & & ROP & 0 \\
\hline & & & & & Others $^{\mathrm{a}}$ & 2100 \\
\hline
\end{tabular}

CNS, central nervous system; ROP, retinopathy of prematurity.

${ }^{a}$ Mostly unavoidable causes such as congenital anomalies, optic atrophy, cortical visual impairment, retinal dystrophies.

America and the former socialist economies, ${ }^{7}$ whereas the sequelae of prematurity are important in affluent countries. $^{8}$

\section{Development and blindness in children}

Distal risk factors that influence the incidence of blindness in children at the population level are poverty and low levels of socio-economic development.
The United Nations Development Programme uses a composite index to assess development (the Human Development Index) and between 1975 and 1990, all regions demonstrated improvement in levels of development. ${ }^{9}$ Since 1990 all regions have continued to improve (apart from the former socialist economies that demonstrated a temporary decline) with the exception of sub-Saharan Africa, where development is going backwards. The gap between the 'haves' and the 'have 


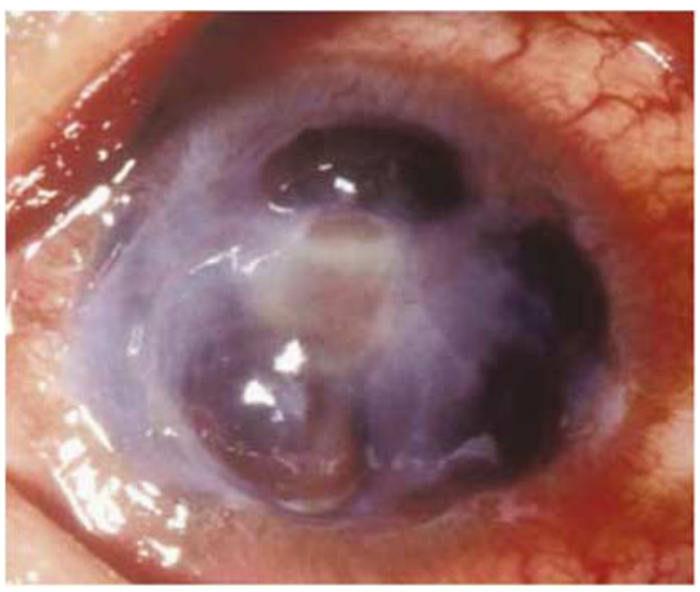

Figure 2 Perforating corneal ulceration from gonococcal kerato-conjunctivitis in a girl from Sierra Leone following the use of infected urine as a traditional remedy for conjunctivitis.

nots' is, therefore, becoming even wider. As far as blindness in children is concerned, low levels of development lead to poor primary health care (eg inadequate nutrition; poor water supplies and sanitation; lack of essential drugs), potentially harmful cultural practices (eg use of traditional remedies) and low level of education among mothers. Inadequate primary eye care and clinical services for children mean that children with treatable causes of blindness remain blind, and lack of support services results in blind children who are unable to participate fully in society.

The major causes of blindness in children that are directly associated with poverty are vitamin A deficiency and measles. Measles infection is more serious in sub-Saharan Africa than in other parts of the world with a far higher case fatality rate. ${ }^{10}$ This is because in Africa many children have pre-existing illnesses or are malnourished; overcrowding leads to a high infecting dose $^{11}$ and services to treat complications are not readily available. Measles is also highly infectious, with a basic reproductive rate of 15 , which means in 'virgin', non-immune populations, one infected individual passes the infection on to 15 others, on average. To prevent epidemics, very high levels of immunity are, therefore, required. Measles immunization coverage has increased dramatically in many countries, with a concomitant drop in the number of cases of measles and measles related deaths. However, there are still approximately 450000 cases annually, and 15 countries (most in sub-Saharan Africa) have an incidence of more than $50 / 100000 \cdot{ }^{12}$ Measles immunization coverage was $<50 \%$ in five African countries in 2004, and $50-79 \%$ in $>20$ other countries. Improving immunization coverage in Africa will require political will, ongoing donor support, strengthening health systems, and increasing awareness among the population of the benefits of immunization.

Vitamin A deficiency is another important potentially blinding condition of poverty. Distal causes include ecological conditions that make growing vitamin A-rich foods difficult; national and international policies that promote cash cropping; poor land rights; political instability; poor infrastructure for transporting vitamin A-rich foods, etc. Household risk factors are poor water supplies and sanitation; lack of land ownership; illiterate mothers and large family sizes. Individual children can be precipitated into acute, blinding xerophthalmia by diarrhoea and febrile illnesses, including measles infection. Since the 1980s, when clinical trials conclusively showed that vitamin A deficiency is an important cause of child mortality, ${ }_{1}^{13}$ there have been concerted efforts at control. Short-term strategies include 6 monthly supplementation with high-dose vitamin A, which can be given at the time of immunization.

Medium-term strategies involve food fortification, food supplements and dietary diversification. In the longterm, the answer lies in improving development. Control initiatives are having a major impact on the number of children with vitamin A deficiency, and the global estimates showed a drop from 5 to 3.3 million over the decade from 1985, and targets have been set for the elimination of vitamin A as a public health problem, with the target for Africa being the year 2015. Again, control will require ongoing commitment, resources and international political will to address poverty, particularly in Africa.

Improving economies can afford to expand or introduce new services and improved provision for premature babies as a result of the expansion in neonatal care is one reason for the 'third epidemic' of blindness due to ROP being experienced in many of the middle income countries of Latin America and the former socialist economies of eastern and central Europe. ROP is also increasingly being reported from urban centres in Asia, including India, ${ }^{14}$ China, ${ }^{15}$ Thailand ${ }^{16}$ and Vietnam..$^{17}$ The available data seem to suggest that countries fall into three groups with respect to the risk of blindness due to ROP. ${ }^{18}$ In very poor countries with high infant mortality rates (ie $>60 / 1000$ live births), ROP is not a problem as neonatal care services are generally not available, or premature babies die before developing ROP. In affluent countries with very low infant mortality rates (ie $<8 / 1000$ live births) the risk of ROP as a cause of blindness in children is also low, as neonatal care is usually excellent and programmes for detecting babies with treatable disease are being implemented. It is countries with infant mortality rates in the range of 8-60/1000 live births that are most likely to have ROP as an important cause of blindness (Figure 3). In these 


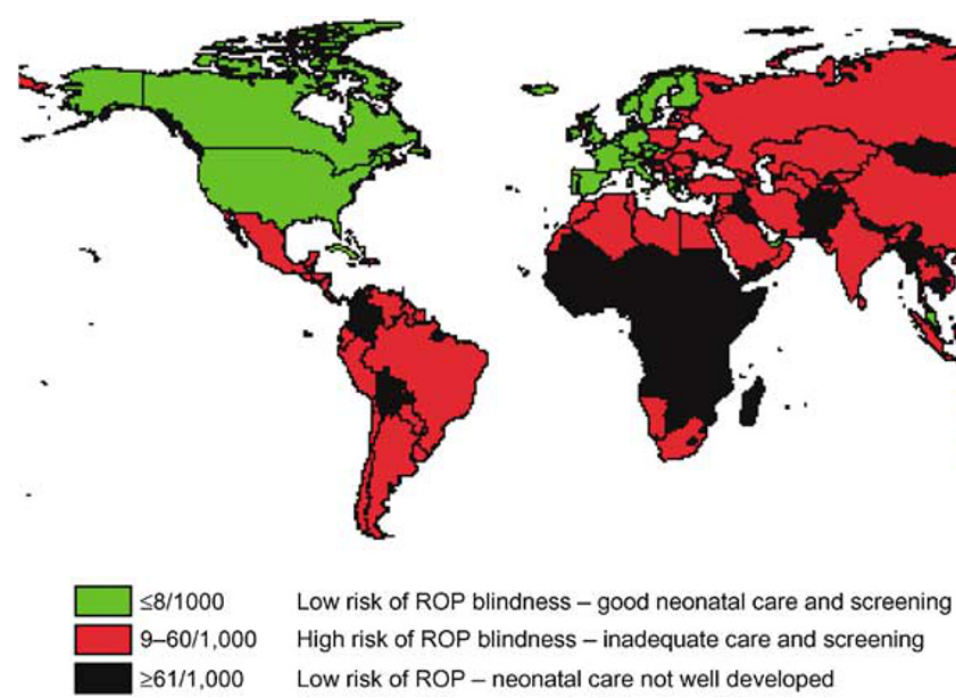

Figure 3 Probable distribution of blindness in children due to retinopathy of prematurity as a public health problem, using infant mortality rates as a proxy indicator.

middle-income countries, ROP can account for up to $60 \%$ of blindness. This explosion has been referred to as the third epidemic, as babies with severe ROP have characteristics of first epidemic babies (ie birth weights averaging $1300 \mathrm{~g}$ ) as well as second epidemic babies (ie mean birth weight of around $750 \mathrm{gs}) .{ }^{19}$ The implications are that programmes for detecting babies with treatable disease need to include bigger, more mature babies, which significantly increases the number of babies that need to be examined. In many countries, this is occurring against a backdrop of an absolute, or relative lack of ophthalmologists with the necessary skills, motivation or time. Awareness of the need for, and provision of ROP programmes is gaining pace, certainly in Latin America. Nurses who work on neonatal units can play a key role in preventing ROP, by avoiding excessive use of supplemental oxygen and by ensuring babies are closely monitored, but many are unaware of ROP and its risk factors. Further research is needed to determine whether telemedicine with remote reading of digital images can provide a case detection service that is safe, feasible, reliable and cost effective. ${ }^{20}$

\section{Patients' perspectives}

There are many inter-related factors that influence whether parents access services for their children. As children with visual problems usually do not complain, they are dependent on their parents identifying and acknowledging that there is a problem and their subsequent health-seeking behaviour. Cultural beliefs that congenital blindness cannot be cured, for example, or that the condition arose as a consequence of angering ancestral spirits, will influence how parents behave, and who they take their child to, if at all. Very poor families who live in remote rural areas have to make difficult choices about how to use their limited resources, and families on the borderline of subsistence may not consider a child's sight a priority, or they may be more willing to invest scarce resources (money as well as time and effort) in a son rather than a daughter. For many, hospitals are unwelcoming and frightening places, and this is particularly so for rural families who have to travel to, and often stay in cities. In many cultures, women need to be accompanied by a male head of household, which means the whole family has to travel, which adds to the direct and opportunity costs. All these factors mean that parents may resort to home remedies or traditional practices, which may be harmful. Certainly in Africa, use of traditional remedies is common, such as urine, which may be infected with gonococcus, or sap or infusions made from plant material that can introduce fungi. Visual loss can result directly from ocular trauma (chemical, thermal or physical) or from superimposed infection, or as a result of the delay in obtaining appropriate treatment.

A study from Tanzania showed that children with cataract delayed an average of 34 months before presenting to a tertiary eye centre, and that the risk of delay was greater if the mother had low socio-economic status. ${ }^{21}$ Similar findings have been found in a study in Bangladesh, in which $>80 \%$ of 528 children identified in the community who were blind from cataract had never attended an eye department (M Muhit, personal communication). The implications of these findings are that case finding needs to be proactive, using novel methods such as key informants, or by training primary eye care workers. Health education is also required so 
that parents of children with eye problems understand the condition and the need for an early assessment by eye care professionals.

In some regions, consanguinity is widely practiced, and is deeply rooted in communities because of the social and economic benefits. However, the downside is the increased risk of autosomal-recessive diseases, including blinding eye conditions. In these settings, genetic risk counselling services need to be established cautiously as blame can be apportioned, with the mother often being held responsible. In a small study in Egypt, mothers often attended genetic counselling services without their husbands and some were fearful that if their husbands found out that the condition was passed from parents to children, they would be ostracised and the husband would take another wife. Fatalistic views may also result in parents not acting on the advice they receive (Gomaa, A., personal communication). ${ }^{22}$

More region-specific qualitative research is needed in this area, to explore the knowledge, perceptions and behaviours of parents of blind children and of the children themselves. This information can be used to develop health promotion and education strategies relevant to the local situation.

\section{Providers' perspectives}

The control of blindness in children is a priority of VISION2020 - the right to sight, and targets have been set for disease control as well as the level of services required. ${ }^{2}$ For example, it has been recommended that one child eye care centre, with a well-trained team led by a paediatric ophthalmologist, be established for every 10 million population by the year 2020. Secondary, district level services also need to be strengthened so that ophthalmologists and other members of the eye care team know how to manage less complex cases, and have an understanding of visual development. Certainly in developing countries where there is the potential for primary prevention of conditions leading to corneal scarring, primary eye care that specifically includes control of blindness in children is also essential. Clear referral mechanisms are also required between the different levels of service provision, with links to government departments and/or agencies, who provide education and rehabilitation services for incurably visually impaired and blind children. These services can only be developed if control of blindness in children is a specific objective of national plans for the prevention of blindness, and if there are policies for subspeciality training and positions created for individuals in appropriate eye departments after training.

Since VISION2020 was launched in 1999, many countries have revised their national plans, and in 2003, as a result of intense advocacy, a resolution was passed by the World Health Assembly urging all member states to develop national prevention of blindness plans, in partnership with the World Health Organization and in collaboration with non-governmental organizations and the private sector. ${ }^{22}$ Member states are also urged to establish a national coordinating committee to help develop and implement the plans by 2007 at the latest. Many countries now specifically include control of blindness in children in their national plans, and this is leading to an expansion of tertiary level, child friendly services for children. Training centres are being established in Africa and Asia, which promotes southsouth training, and in some institutions there is capacity for team training (ie ophthalmic nurses, anaesthetists, optometrists/refractionists, low vision specialists as well as ophthalmologists). In countries with high population densities, and reasonable infrastructure for transport, such as India, Bangladesh and Pakistan, having one child eye centre for every 10 million population means that the services will be accessible to a reasonably high proportion of the population. However, in other regions, particularly Africa, where population densities are often low, distances between rural to urban areas are large, and where transport systems are poorly developed and expensive, the emphasis will need to be strengthening of the district level.

A challenge in the provision of eye care services for children has been the lack of equipment for diagnosis and assessment of children, and of consumables appropriate for children (eg low cost, high-quality spectacle frames and IOLs for infants). Two resource centres have recently been established, one in Hong Kong and the other in South Africa, which source and bulk purchase equipment and consumables, thus increasing access and keeping the cost as low as possible.

\section{Summary}

The VISION2020 target for control of blindness in children is to reduce the global prevalence from $0.75 / 1000$ to $0.4 / 1000$ children by 2020 , but strategies and national plans need to be responsive to changing priorities, which in turn reflect changes in socioeconomic development. The economies of many developing countries, particularly in Asia, are improving, which together with child survival programmes are having a major impact on corneal scarring - in these counties cataract is now assuming greater importance. In middle-income countries and the emerging economies of Asia, ROP is now a major challenge. However, Africa, where $10 \%$ of the world's population live, is home to almost $1 / 4$ of the world's blind children. The pendulum of development is 
swinging backwards in the region, and health-care systems are weak. Controlling blindness in children in Africa is likely to remain a challenge for years to come.

\section{References}

1 Gilbert CE, Anderton L, Dandona L, Foster A. Prevalence of blindness and visual impairment in children - a review of available data. Ophthal Epidemiol 1999; 6: 73-81.

2 World Health Organization, Geneva, 1999. Preventing blindness in children. WHO/PBL/00.77.

3 Sommer Alfred, Davidson Frances R. Assessment and control of vitamin A deficiency: The Annecy Accords. Proceedings of the XX International Vitamin A Consultative Group Meeting. Am Soc Nutr Sci 2002; (Suppl 2): 845S-850S.

4 Gilbert C, Foster A, Negrel D, Thylefors B. Childhood blindness: a new form for recording causes of visual loss in children. Bull WHO 1993; 71: 485-489.

5 Gilbert CE, Foster A. Childhood blindness in the context of VISION 2020 - the Right to Sight. Bull WHO 2001; 79: 227-232.

6 Waddel KM. Childhood blindness and low vision in Uganda. Eye 1998; 12: 184-192.

7 Gilbert C, Rahi J, Eckstein M, O'Sullivan J, Foster A. Retinopathy of prematurity in middle-income countries. Lancet 1997; 350: 12-14.

8 Jugnoo S Rahi, Noriko Cable. On behalf of the British Childhood Visual Impairment Study Group (BCVISG). Severe visual impairment and blindness in children in the UK. Lancet 2003; 362: 1359-1365.

9 The State of Human Development. In: The UNDP Human Development Report: Cultural liberty in today's diverse world, 2004, pp 134.

10 Semba RD, Bloem MW. Measles blindness. Surv Ophthalmol 2004; 49: 243-255.

11 Aaby P, Coovadia H, Bukh J et al. Severe measles: A reappraisal of the role of nutrition, overcrowding and virus dose. Med Hypotheses 1985; 18: 93-112.
12 www.who.int/.../diseases/measles/en/index.html

13 Sommer A. Child Survival. In: Sommer A and West K (eds) Vitamin A deficiency: Health, survival and vision. Oxford University Press, Oxford, UK, 1996, pp 19-61.

14 Shah PK, Navendran V, Saravanan VR et al. Fulminant retinopathy of prematurity - clinical characteristics and laser outcome. Ind J Ophthalmol 2005; 53: 261-265.

15 Chen Y, Xi L. Characteristics of severe retinopathy of prematurity patients in China: a repeat of the first epidemic? Br J Ophthalmol 2006; 90: 268-271.

16 Trinavarat A, Atchaneeyasakul LO, Udompunturak S. Applicability of American and British criteria for screening for retinopathy of prematurity in Thailand. Jpn J Ophthalmol 2004; 48: 50-53.

17 Phan MH, Nguyen PN, Reynolds JD. Incidence and severity of retinopathy of prematurity in Vietnam, a developing middle income country. J Pediatr Ophthalmol Strab 2003; 40: 193.

18 Gilbert C. Retinopathy of prematurity: a global perspective of the epidemics, population of babies at risk and implications for control. Early Human Development (in press).

19 Gilbert C, Fielder A, Gordillo L, Quinn G, Semiglia R, Visintin $\mathrm{P}$ et al. On behalf of the International NO-ROP Group. Characteristics of babies with severe retinopathy of prematurity in countries with low, moderate and high levels of development: implications for screening programmes. Pediatrics Electronic Pages 2005; 115: 518-525.

20 Chiang MF, Starren J, Du YE, Keenan JD, Schiff WM, Barile GR et al. Remote image based retinopathy of prematurity analysis of accuracy diagnosis: a receiver operating characteristic analysis of acuracy. Br J Ophthalmol 2006; 90: 1292-1296.

21 Mwende J, Bronsard A, Mosha M, Bowman R, Geneau R, Courtright P. Delay in presentation to hospital for surgery for congenital and developmental cataract in Tanzania. $\mathrm{Br} \mathrm{J}$ Ophthalmol 2005; 89: 1478-1482.

22 World Health Organisation, Geneva. Elimination of avoidable blindness. Resolution of the fifty-sixth World Health Assembly, 28 May 2003, agenda item 14.17. WHA 56.26 . 